\title{
Effects of Phosphate Buffer Capacity on Critical Levels and Relationships between Soil Tests and Labile Phosphate in Wheat-growing Soils
}

\section{C. R. Holford}

New South Wales Department of Agriculture, Agricultural Research Centre, Tamworth, N.S.W. 2340.

\section{Abstract}

Thirty-nine soils from northern New South Wales were used to examine the effects of phosphate buffer capacity on (i) the extraction of labile phosphate by four soil tests, (ii) the relationships between the four soil tests, and (iii) the critical level of each soil test required for near-maximum yield of wheat under field conditions.

The results confirmed the principle, recently proposed by the author, that the larger the negative effect of buffer capacity on extraction of labile phosphate by a soil test, the higher is the correlation between the soil test and plant yield response to phosphate. The acidic ammonium fluoride extractant of Bray and Kurtz was the most sensitive to buffering in this respect, while the alkaline sodium bicarbonate extractant of Olsen et al. was less sensitive and the modified sodium bicarbonate test of Colwell least sensitive to buffering. Whereas a previous glasshouse study suggested that the ammonium fluoride test was over-sensitive to buffering, and hence underestimated available phosphate in strongly buffered soils, this field study showed that the test is correctly sensitive to buffering. Consequently critical levels for near-maximum wheat yields do not vary for the ammonium fluoride tests, but increase with increasing buffer capacity for the sodium bicarbonate tests. The additional measurement of buffer capacity is therefore required to give precision in the use of the sodium bicarbonate soil test and particularly the Colwell test.

The results also suggest that a high correlation between two soil tests can only be expected where each test is similarly sensitive to buffering, provided of course that both tests extract phosphate mainly from the labile pool.

\section{Introduction}

It is generally accepted that values obtained by different soil test procedures are not always highly correlated, and it is believed that this is caused by variations in soil composition which affect phosphorus solubility (Colwell and Donelly 1971). While this may be generally true, it is important to realize that the major soil phosphate characteristic controlled by soil composition is the buffer capacity (Holford 1977). In this context phosphate buffer capacity may be defined as the resistance of the soil solution concentration to change when phosphate is added to or removed from the labile pool (Holford and Mattingly 1976). It has been shown recently that the amounts of labile phosphate extracted by some soil tests tend to decrease with inoreasing buffer capacity of the soils (Holford and Mattingly 1979). Because the magnitude of this effect, and hence the relative sensitivity to buffer capacity, varies between soil tests, it is reasonable to suppose that buffer capacity is an important soil property influencing inter-relationships between soil tests; particularly those that extract phosphate only from the labile pool (Holford 1980). 
It was also shown by Holford and Mattingly (1979) that the more sensitive a soil test is to buffer capacity, the better the correlation between the soil test values and phosphorus uptake by ryegrass. However, in a subsequent study, using white clover on a much more variable group of soils, Holford (1980) found that the relative efficacy of a soil test may be affected by its over-sensitivity as well as undersensitivity to buffering. A soil test which is over-sensitive will underestimate available phosphate on strongly buffered soils, while a soil test which is under-sensitive will overestimate it. Either of these two conditions will cause the critical levels of a soil test to be affected by variations in buffering.

The importance of the degree of sensitivity of various soil tests to buffer capacity, demonstrated in the above studies, applies only to potted soils in the glasshouse. Buffering is likely to be even more important in field soils, where plant roots explore a given volume of soil much less effectively than in the restricted volume of a pot. Whether a soil test, which must simulate the plant root system in the extraction of labile phosphate, is over-sensitive or under-sensitive to buffering may therefore alter between a glasshouse and a field environment.

For this reason the following study was carried out, using field experimental data for wheat grown on 39 soils in northern New South Wales by Colwell and Esdaile (1968). The aims were to examine the effects of buffer capacity on (i) the extraction of labile phosphate by four soil tests which were thought to remove phosphate mainly from the labile pool, (ii) the relationships between the four soil tests, and (iii) the critical level of each soil test for near-maximum yield of wheat under field conditions. The same soil tests were used as in the previous glasshouse study (Holford 1980), except for the Mehlich test which was found to extract large quantities of non-labile phosphate.

\section{Materials and Methods}

Some soil chemical data for the 39 soils, taken from the upper $7 \cdot 5 \mathrm{~cm}$ layer, were previously reported by Colwell and Esdaile (1968). Soil pH (5:1, water : soil) varied from $5 \cdot 5$ to $8 \cdot 1$, and 29 soils had a $\mathrm{pH}$ greater than $6 \cdot 0$. Duplicate samples of these soils, which were retained air-dried in sealed bottles in the Tamworth laboratories, were chemically analysed for the following phosphate parameters: buffering index (Holford 1979), labile phosphate (Holford et al. 1974), sodium bicarbonate-extractable phosphorus (Olsen et al. 1954; Colwell 1963), and 0.03 $\mathrm{M}$ ammonium fluoride $+0.025 \mathrm{~N}$ (or $0.1 \mathrm{~N}$ ) hydrochloric acid-extractable phosphorus (Bray and Kurtz 1945). The last four soil test analyses will be referred to as the Olsen, Colwell, Bray ${ }_{1}$ and Bray $_{2}$ tests respectively. Phosphorus-free activated carbon, at about $40 \mathrm{mg} / \mathrm{g}$ soil, was used in the sodium bicarbonate extractions to minimize the effects of organic matter coloration. In all cases equilibration was done on an orbital shaker (200 r.p.m.) at $25 \pm 1^{\circ} \mathrm{C}$, and the soil test extracts analysed for phosphorus by the Murphy and Riley procedure (1962).

Wheat yield response data of Colwell and Esdaile (1968) were converted to relative yields by expressing grain yield in the absence of applied phosphate as a percentage of the maximum yield with applied phosphate. The relationships between relative yield and soil test were linearized by plotting soil test/relative yield against soil test. The slope and intercept from this linear regression were then used to calculate fitted curves from the equation, 


$$
Y=k y_{m} P /(1+k P),
$$

where $k=$ slope/intercept, $y_{m}=1 /$ slope, $Y=$ calculated relative yield, and $P=$ soil test value. These curves were used to determine soil test critical levels which were arbitrarily chosen as the soil test value corresponding to $90 \%$ of maximum yield.

The effects of buffering index on the relationships between soil tests and labile phosphorus, soil test and relative yield, and interrelationships between soil tests were evaluated from simple and multiple regression analyses. In addition, the soils were divided into three groups according to their buffering indices, and simple correlation coefficients and regressions for each of the three groups were calculated. These relationships were used to illustrate the major effect of buffering on each parameter.

Table 1. Means, ranges and standard deviations for soil and plant variables within each phosphate buffering class of soils

\begin{tabular}{|c|c|c|c|c|c|c|c|c|c|}
\hline \multirow[t]{2}{*}{ Variables } & \multicolumn{3}{|c|}{ Weakly buffered } & \multicolumn{3}{|c|}{ Moderately buffered } & \multicolumn{3}{|c|}{$\begin{array}{c}\text { Strongly to } \\
\text { very strongly buffered }\end{array}$} \\
\hline & Mean & Range & sD & Mean & Range & SD & Mean & Range & SD \\
\hline Buffering index $(\mathrm{ml} / \mathrm{g})$ & 325 & $169-435$ & 90 & 664 & $455-1111$ & 207 & 2222 & $1667-2500$ & 481 \\
\hline Labile P ( $\mu \mathrm{g} / \mathrm{g}$ soil) & $27 \cdot 1$ & $14-61$ & $13 \cdot 9$ & $40 \cdot 1$ & $20-137$ & $28 \cdot 6$ & $68 \cdot 7$ & $53-81$ & $14 \cdot 3$ \\
\hline Colwell $\mathrm{P}(\mu \mathrm{g} / \mathrm{g}$ soil $)$ & $22 \cdot 2$ & $8 \cdot 8-62 \cdot 6$ & $15 \cdot 8$ & $28 \cdot 0$ & $7 \cdot 0-124$ & $30 \cdot 4$ & $35 \cdot 5$ & $28 \cdot 4-40 \cdot 0$ & $6 \cdot 2$ \\
\hline Olsen P $(\mu \mathrm{g} / \mathrm{g}$ soil $)$ & $11 \cdot 5$ & $5 \cdot 2-36 \cdot 0$ & $7 \cdot 9$ & $12 \cdot 7$ & $4 \cdot 0-54 \cdot 2$ & $12 \cdot 8$ & $14 \cdot 0$ & $10 \cdot 6-18 \cdot 1$ & $3 \cdot 8$ \\
\hline Bray $P_{1}(\mu \mathrm{g} / \mathrm{g}$ soil $)$ & $12 \cdot 1$ & $2 \cdot 0-50 \cdot 0$ & $12 \cdot 3$ & $9 \cdot 5$ & $1 \cdot 1-34 \cdot 7$ & $9 \cdot 0$ & $4 \cdot 0$ & $3 \cdot 2-4 \cdot 8$ & 0.8 \\
\hline Bray $\mathrm{P}_{2}(\mu \mathrm{g} / \mathrm{g}$ soil $)$ & $24 \cdot 3$ & $8 \cdot 1-115$ & $26 \cdot 5$ & $25 \cdot 6$ & $4 \cdot 3-188$ & $45 \cdot 6$ & $7 \cdot 8$ & $4 \cdot 3-10 \cdot 5$ & $3 \cdot 2$ \\
\hline Relative yield (\%) & $78 \cdot 9$ & $64-101$ & $12 \cdot 2$ & $70 \cdot 2$ & $57-95$ & $13 \cdot 7$ & $60 \cdot 4$ & $45-78$ & $16 \cdot 6$ \\
\hline
\end{tabular}

\section{Results and Discussion}

Means, ranges and standard deviations for soil and plant variables within each phosphate buffering class of soils are given in Table 1 . Of the 39 soils, 21 were weakly buffered, with indices of less than $440 \mathrm{ml} / \mathrm{g}, 15$ were moderately buffered $(455-1110 \mathrm{ml} / \mathrm{g})$, one was strongly buffered $(1670 \mathrm{ml} / \mathrm{g})$, and two were very strongly buffered $(2500 \mathrm{ml} / \mathrm{g})$.

Table 2. Effects of buffer capacity ${ }^{A}$ on extraction of labile phosphorus by four soil tests

\begin{tabular}{|c|c|c|c|}
\hline Soil test & $\begin{array}{c}\text { Variance } \\
\text { Labile P } \\
\text { only } \\
(\%)\end{array}$ & $\begin{array}{c}\text { nted for by: } \\
\text { Labile } \mathrm{P}+ \\
\text { buffering } \\
(\%)\end{array}$ & $\begin{array}{c}\text { Difference } \\
(\%)\end{array}$ \\
\hline Bray $P_{2}$ & 55 & 91 & 36 \\
\hline Bray $P_{1}$ & 31 & 65 & 34 \\
\hline Olsen & 70 & 88 & 18 \\
\hline Colwell & 79 & 90 & 11 \\
\hline
\end{tabular}

It is interesting to observe the overall trends in each soil and plant variable (Table 1) with increasing buffer capacity: There was a distinct increase in labile phosphate, showing that increasing buffer capacity raises the ability of soils to retain phosphate, from whatever source, in the labile pool against depletion by leaching and plant uptake. The corresponding decrease in relative yield showed that phosphate deficiency tended to be greater on strongly buffered than on weakly buffered soils. 


\section{Effects of Buffering on Extraction of Labile Phosphate}

The effects of buffer capacity can be seen in Table 2, which shows the extra variance accounted for by buffer capacity in multiple regressions of soil test value on quantity of labile phosphate. All four soil tests were correlated $(P<0.001)$ with labile phosphate, but the sodium bicarbonate tests were the most highly correlated. However, in spite of this high correlation, buffer capacity had a very significant $(P<0.001)$ negative effect on the extraction of labile phosphate by each soil test, the smallest effect being on the Colwell test and the largest effect on the Bray tests. This is illustrated in Fig. 1, which shows that the proportion of labile phosphate extracted from strongly buffered soils was depressed most in the Bray tests and least in the Colwell test. Whereas the $\mathrm{Bray}_{2}$ test extracted more phosphate from weakly buffered soils than the Colwell test, it extracted much less phosphate from strongly buffered soils. A similar comparison may be made between the Bray ${ }_{1}$ test and the Olsen test. These results therefore support the previous study (Holford 1980) and show that the extraction of labile phosphate is most sensitive to buffering in the Bray test and least sensitive in the Colwell test.

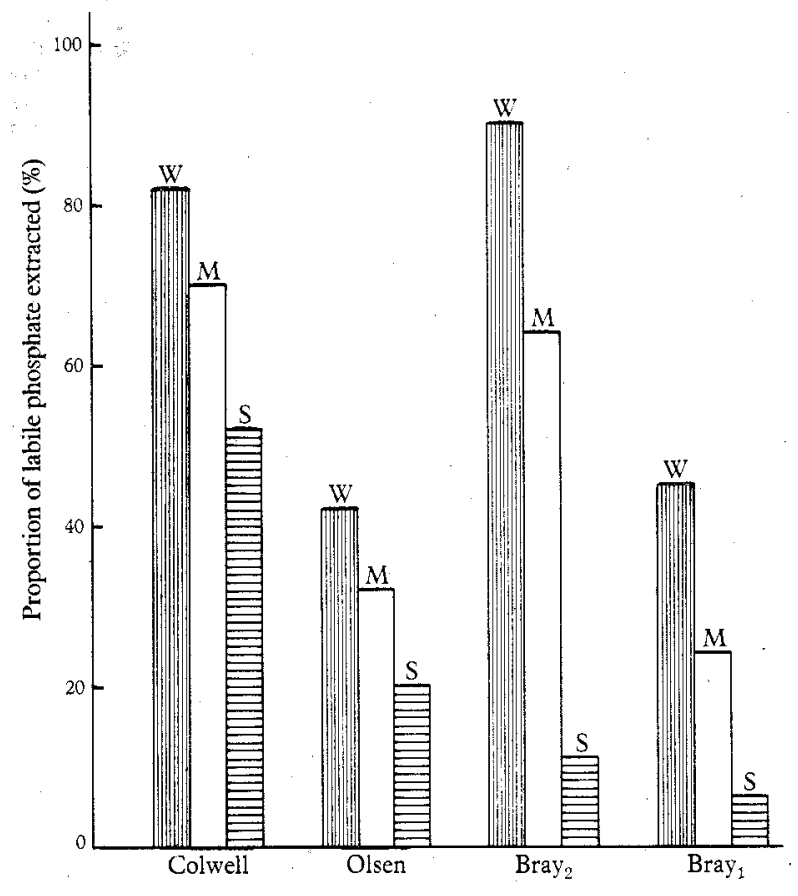

Fig. 1. Effect of buffer capacity on proportion of labile phosphate extracted by each soil test. W, Weakly buffered soils. M, Moderately buffered soils. S, Strongly buffered soils.

The mean values for each soil test given in Table 1 also illustrate their relative sensitivities in that Colwell phosphate increased markedly, Olsen phosphate increased slightly, while Bray phosphate decreased with increasing buffer capacity.

\section{Effects of Buffering on Relationships between Soil Tests}

The effects of buffer capacity on relationships between soil tests are illustrated in Fig. 2 in which the soil test which was least sensitive to buffering is placed on the ordinate and the most sensitive on the abscissa for each pair of comparisons. In general, the more similar the two soil tests were in their sensitivity to buffering, the 
higher the correlation between them. This applies to the correlation between the two Bray tests $(r=0.95)$ and that between the two sodium bicarbonate tests $(r=0.98)$. On the other hand, the Colwell and Bray 1 tests were the most dissimilar and they were the most weakly correlated $(r=0.75)$. There were corresponding weak correlations between the sodium bicarbonate and Bray $_{2}$ tests.

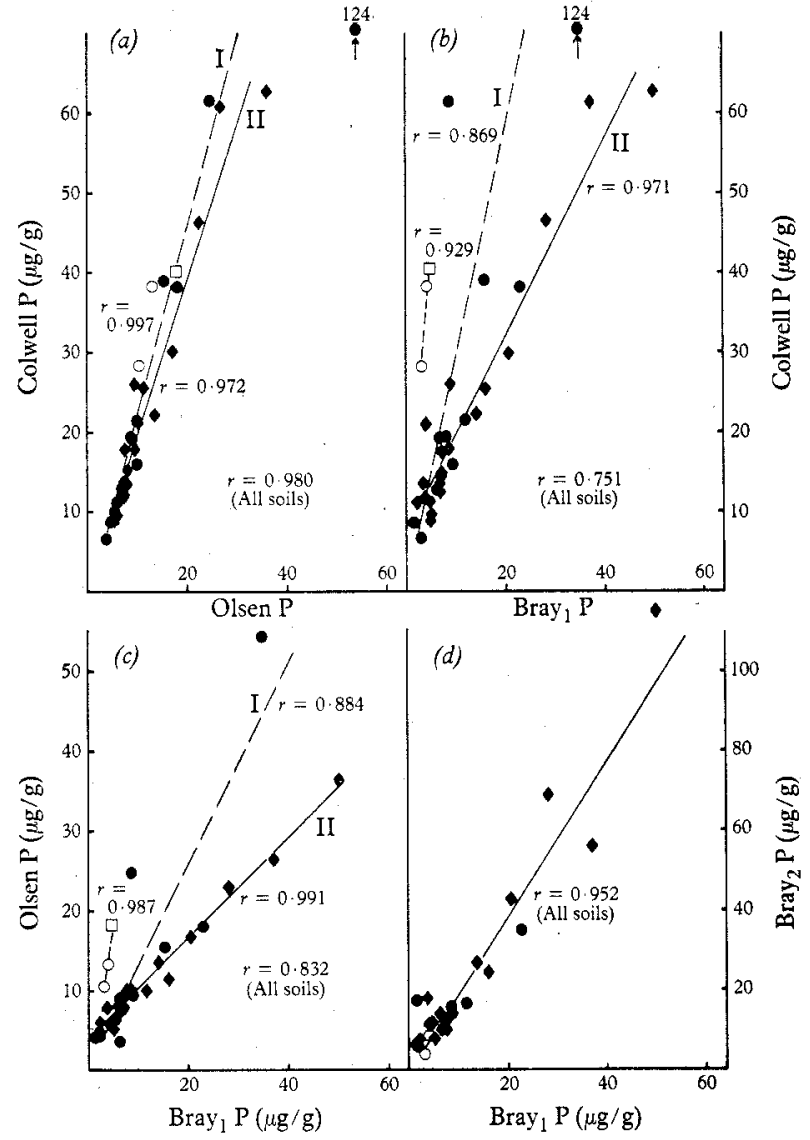

Fig. 2. Effect of buffer capacity on inter-relationships between soil tests.

Weakly buffered soils.

$\bullet-\ldots$ Moderately buffered soils.

口 Strongly buffered soils. 0...... Very strongly buffered soils.

(a) I: $\mathrm{P}_{\mathrm{c}}=2 \cdot 37 \mathrm{P}_{0}-2 \cdot 3$

II: $\mathrm{P}_{\mathrm{c}}=1.95 \mathrm{P}_{0}-0.2$

(b) I: $\mathrm{P}_{\mathrm{c}}=2 \cdot 93 \mathrm{P}_{\mathrm{B} 1}$

II: $\mathrm{P}_{\mathrm{c}}=7 \cdot 1+1 \cdot 24 \mathrm{P}_{\mathrm{B} 1}$

(c) I: $\mathrm{P}_{0}=0.8+1.25 \mathrm{P}_{\mathrm{B} 1}$

II: $\mathrm{P}_{0}=3 \cdot 9+0.63 \mathrm{P}_{\mathrm{B} 1}$

(d) $\quad \mathrm{P}_{\mathrm{B} 2}=1.98 \mathrm{P}_{\mathrm{B} 1}-0.3$.

Stratification of the soils according to their buffering index caused a marked improvement in the correlations and regressions wherever the two soil tests were dissimilar in their sensitivities to buffering (Fig. 2). This applies to the correlation between the Olsen and Bray 1 tests, and between the Colwell and Bray 1 tests. In each case the regression lines for each buffering class were distinctly different in both position and slope. These results suggest that a high correlation between two soil tests can only be expected where each test is similarly sensitive to buffering, provided of course that both tests extract phosphate only from the labile pool (Holford 1980).

\section{Effects of Buffering on Soil Test Critical Levels}

Because of the curvilinear relationships between relative yield and soil test (Fig. 3), a quadratic model was used in these regression analyses. The Bray tests accounted 
for the largest proportion of the variance in relative yield and the Colwell test the smallest (Table 3). Note that this is the opposite order to that for the correlations between soil tests and labile phosphate (Table 2). However in addition, buffer capacity had no effect on the relationships between the Bray tests and relative yield, whereas it had a very significant effect $(P<0.001)$ on the relationships between the sodium bicarbonate tests and relative yield (Table 3 ). Thus the greater the negative effect of buffering on the extraction of labile phosphate by the soil test (Table 2 and Fig. 1), the higher was the correlation between the soil test and relative yield.

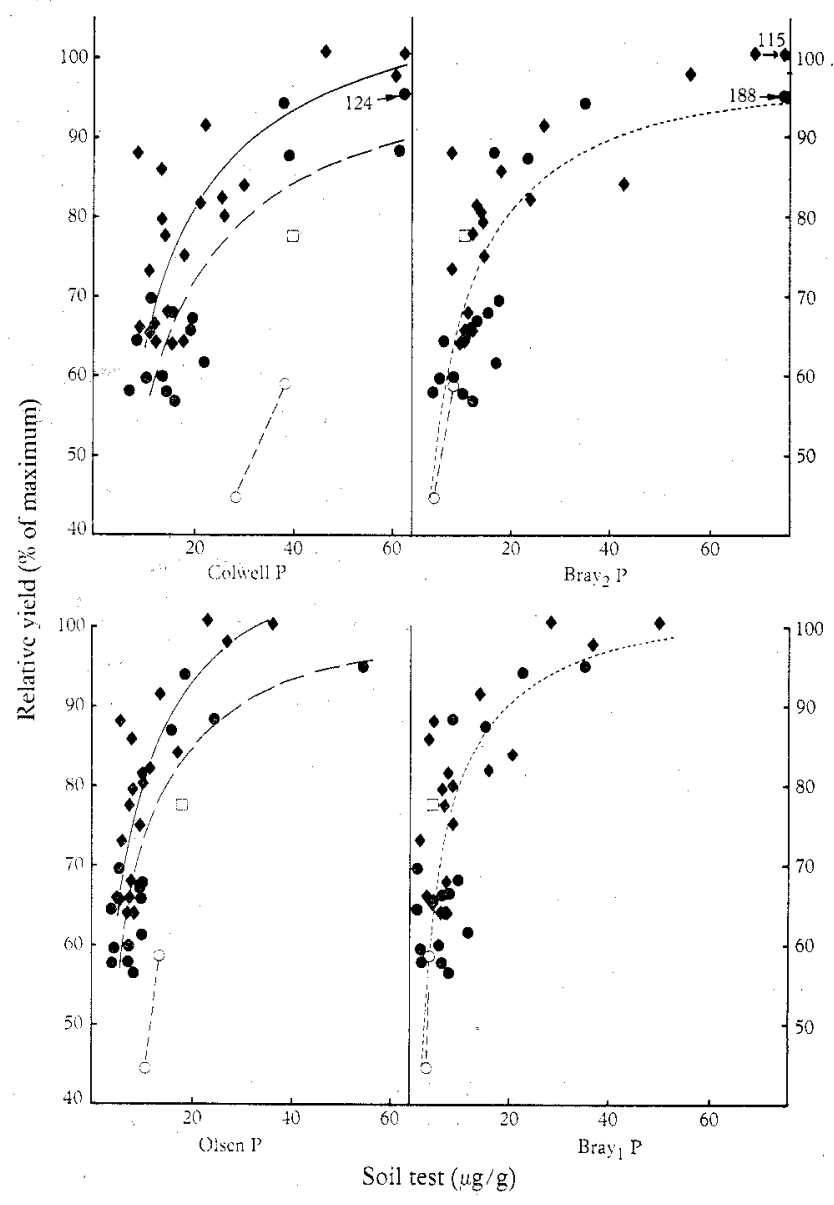

Fig. 3. Effect of buffer capacity on relative yield of wheat grain in relation to soil test. Symbols as in Fig. 2.

Relative yield curves, fitted to each buffering class of soils (Fig. 3), were well separated for the sodium bicarbonate tests; the higher the buffer capacity, the lower the relative yield at any particular soil test value. By contrast there appeared to be no consistent effect of buffer capacity on the position of the points for the Bray tests, so that a single curve appeared to give a satisfactory fit to all soils regardless of their buffer capacity. It follows that a common soil test value corresponded to $90 \%$ of maximum yield for each of the Bray tests regardless of the buffer capacity, whereas the critical soil test level increased with increasing buffer capacity for each 
of the sodium bicarbonate tests. Because of the larger effect of buffering on the yield : soil test relationship for the Colwell test (Table 3), the critical levels of this test were the most sensitive to differences in buffer capacity.

Table 3. Effects of buffer capacity ${ }^{A}$ on quadratic relationships between relative yield and soil tests

\begin{tabular}{lcccc}
\hline Soil tests & $\begin{array}{c}\text { Variance accounted for by: } \\
\text { Soil test } \\
\text { only } \\
(\%)\end{array}$ & $\begin{array}{c}\text { Soil test }+ \\
\text { buffering } \\
(\%)\end{array}$ & Difference & $\begin{array}{c}\text { Significance } \\
\text { of } \\
\text { buffering } \\
(\% \text { prob. })\end{array}$ \\
\hline Bray $\mathbf{P}_{2}$ & 62 & 65 & $(\%)$ & Ns \\
Bray $\mathbf{P}_{1}$ & 56 & 60 & 3 & Ns \\
Olsen $P$ & 51 & 74 & 23 & $<0 \cdot 1$ \\
Colwell P & 40 & 72 & 32 & $<0 \cdot 1$ \\
\hline
\end{tabular}

A Buffer capacity had a negative effect on relative yield for all soil tests.

Although the sodium bicarbonate tests were inferior to the Bray tests in their relationship with the relative yield, when buffer capacity was included in a multiple regression the sodium bicarbonate tests accounted for rather more of the variance in relative yield than the Bray tests (Table 3). It may be concluded therefore that the sodium bicarbonate tests will be more precise in their prediction of relative yield, provided critical levels are adjusted according to the buffer capacities; otherwise the Bray tests will be more precise.

\section{General Discussion}

This is the third study reported by the author that has demonstrated the principle that the larger the negative effect of buffering on extraction of labile phosphate by a soil test, the higher is the correlation between the soil test and either phosphorus uptake by the plant or plant yield response to phosphate. These studies have covered a homogeneous group of 24 soils growing ryegrass under glasshouse conditions in England (Holford and Mattingly 1979), a heterogeneous group of 30 soils growing white clover under glasshouse conditions in New South Wales (Holford 1980), and now a heterogeneous group of 39 soils growing wheat under field conditions in New South Wales. This last study has demonstrated that a soil test (i.e. the Bray test) which appears over-sensitive to buffering in the glasshouse (Holford 1980) is correctly sensitive to buffering in the field. These results show the greater importance of buffer capacity in the field, reflecting the fact that a plant root system will explore a given volume of soil much less effectively in the field than in the pot, and is therefore more sensitive to variations in buffer capacity under field conditions. Hence an apparent over-sensitivity of the Bray test, when evaluated in the glasshouse, translates to a correct degree of sensitivity in the field. The Colwell test was consistently under-sensitive to buffering, and consequently the critical levels for optimum plant growth in the glasshouse, and particularly in the field, require adjustment according to the buffer capacity. These results support the data of Helyar and Spencer (1977), which showed a trend towards an increase in the critical level of the Colwell test with increasing buffer capacity. 
The sodium bicarbonate test of Olsen et al. (1954) was modified by Colwell (1963) to give more reproducible results. In phosphorus fertilizer studies on wheat in southern New South Wales, it was shown that this modification was slightly superior to four other tests, including the Bray ${ }_{1}$ test but not the original Olsen test, on 27 soils (Colwell 1963). However, the relationship between the values of the Colwell test and those of the Bray ${ }_{1}$ test shows that all of these soils were weakly buffered except for two which were moderately buffered. Thus buffering capacity was not an important factor in that study. In a subsequent comparison of the Colwell test with four other soil tests, which excluded the Bray tests, Colwell (1970) found that the ammonium lactate + acetic acid test of Egner et al. (1960) was slightly superior. This reagent is most similar to the Bray reagent, being an acidic anionic desorbent, and Williams (1967) has demonstrated that this test, like the Bray test (Holford 1980), reflects the intensity of labile phosphate more than the quantity. This in effect means that it is more sensitive to buffer capacity because the intensity of labile phosphate is an inverse function of buffer capacity (Holford and Mattingly 1976).

The sensitivity of the Bray $_{1}$ test to buffer capacity explains the observation from earlier soil test studies that the Bray ${ }_{1}$ test is least affected by differences in soil properties in its correlation with plant yield responses to phosphate (MacLean et al. 1953; Fitts 1956). However, it is known that the Bray $_{1}$ test sometimes gives anomalously low values on soils containing more than $10 \%$ calcium carbonate (Smillie and Syers 1972), and it was fortuitous that the 69 Australian soils were predominantly non-calcareous or only slightly calcareous. It is possible that this latter factor would override the advantage of increased sensitivity to buffering and cause the Bray test to be inferior to sodium bicarbonate on highly calcareous soils, particularly as the Olsen test is quite sensitive to buffering (Holford and Mattingly 1979).

The four soil tests used in this study are alike in that they all contain an anionic desorbent (ammonium fluoride or sodium bicarbonate) and therefore extract phosphate mainly from the labile pool, but dissimilar in that ammonium fluoride reagent is acidic ( $\mathrm{pH} 3 \cdot 0$ or below) and sodium bicarbonate reagent is alkaline $(\mathrm{pH} 8 \cdot 5)$. Differences in $\mathrm{pH}$ are unlikely to account for the differences in sensitivity to buffer capacity because of the exclusion of both very acid $(\mathrm{pH}<5 \cdot 5)$ and very alkaline $(\mathrm{pH}>8 \cdot 1)$ soils. The superiority of the Bray reagent is probably because ammonium fluoride is a much stronger desorbent of phosphate than sodium bicarbonate (Kurtz et al. 1946), and this permits a much shorter extraction time and narrower extractant : soil ratio. As a result only the more easily desorbable phosphate is extracted by ammonium fluoride, and the proportion of easily desorbable phosphate in the labile pool will decrease with increasing buffer capacity (Holford and Mattingly 1976). On the other hand, a much longer extraction time and wider extractant : soil ratio are required to enable sodium bicarbonate to remove measurable quantities of labile phosphate from low phosphate soils, and this means that a much more constant proportion of the labile pool is removed. This effect of increasing extraction time and extractant : soil ratio is shown by the higher correlation of the Colwell test than of the Olsen test with labile phosphate. By contrast the Olsen test as modified by Novais and Kamprath (1978), in which the extractant: soil ratio was decreased from $20: 1$ to $10: 1$ and the shaking time from 30 to $10 \mathrm{~min}$, would be more sensitive to buffering than the original test and could be equivalent to the Bray test in this characteristic. However, such a modification would be feasible only on high phosphate soils. It is probably true that any significant alteration of the shaking time and/or 
extractant : soil ratio will alter the sensitivity of a soil test to buffer capacity (Barrow and Shaw 1976), and therefore significantly affect the relationships between soil tests.

The similarity of the Bray and Olsen reagents in extracting phosphate mainly from the labile pool and the dissimilarity in their sensitivity to buffer capacity explain the variation in correlations between soil test values recorded in this study. However, little purpose is served by correlation studies covering a large range of soil tests because they vary so much in their mechanism of extraction. For instance, dilute acid extractants such as the Mehlich reagent $(0.05 \mathrm{~N}$ hydrochloric acid $+0.025 \mathrm{~N}$ sulfuric acid) and $1 \%$ citric acid extract large amounts of non-labile phosphate (Holford and Mattingly 1979; Holford 1980) so that meaningful correlations would not be expected between these and soil tests which extract phosphate only from the labile pool. Likewise it is difficult to interpret the improvement of correlations between dissimilar soil tests by the addition of other empirical soil chemical measurements, as was done by Colwell and Donelly (1971), when hypotheses do not exist to explain the relationships. The high correlation between the Mehlich, Bray and Colwell tests, recorded by Batten et al. (1979) on a number of experimental plots of a single experimental site, would be unlikely to occur on a large range of soils varying widely in their $\mathrm{pH}$ and buffer capacity.

\section{Acknowledgments}

I thank the Australian Wool Corporation for some financial assistance, B. E. Schweitzer for laboratory assistance, and A. C. Gleeson for multiple regression analyses.

\section{References}

Barrow, N. J., and Shaw, T. C. (1976). Sodium bicarbonate as an extractant for soil phosphate. III. Effects of buffering capacity of a soil for phosphate. Geoderma 16, 273-83.

Batten, G. D., Blair, G. J., and Lill, W. J. (1979). Changes in soil phosphorus and pH in a red earth soil during build-up and residual phases of a wheat-clover ley farming system. Aust. J. Soil Res. 17, 163-75.

Bray, R. H., and Kurtz, L. T. (1945). Determination of total, organic and available forms of phosphorus in soils. Soil Sci. 59, 39-45.

Colwell, J. D. (1963). The estimation of the phosphorus fertilizer requirements of wheat in southern New South Wales by soil analysis. Aust. J. Exp. Agric. Anim. Husb. 3, 190-7.

Colwell, J. D. (1970). A comparison of soil test calibrations for the estimation of phosphorus fertilizer requirements of wheat. Aust. J. Exp. Agric. Anim. Husb. 10, 774-82.

Colwell, J. D., and Donnelly, J. D. (1971). Effects of soil composition on the relationships between soil test values for phosphorus fertilizer requirements. Aust. J. Soil Res. 9, 43-54.

Colwell, J. D., and Esdaile, R. J. (1968). The calibration, interpretation, and evaluation of tests for the phosphorus fertilizer requirements of wheat in northern New South Wales. Aust. J. Soil Res. 6, 105-20.

Egner, H., Reihm, H., and Domingo, W. R. (1960). Investigations on chemical soil analysis as the basis for estimating the nutrient status of soil. K. Lantbruk. Hoegnk. Ann. 26, 199-215.

Fitts, J. W. (1956). Soil tests compared with field, greenhouse, and laboratory results. North Carolina Agric. Exp. Stn Tech. Bull, No. 121.

Helyar, K. R., and Spencer, K. (1977). Sodium bicarbonate soil test values and the phosphate buffering capacity of soils. Aust. J. Soil Res. 15, 263-73.

Holford, I. C. R. (1977). Soil properties related to phosphate buffering in calcareous soils. Commun. Soil Sci. Plant Anal. 8, 125-37.

Holford, I. C. R. (1979). Evaluation of soil phosphate buffering indices. Aust. J. Soil Res. 17, 495-504. Holford, I. C. R. (1980). Greenhouse evaluation of four phosphorus soil tests in relation to phosphate buffering and labile phosphate in soils. Soil Sci. Soc. Am. J. 44, 555-9. 
Holford, I. C. R., and Mattingly, G. E. G. (1976). Phosphate adsorption and plant availability of phosphate. Plant Soil 44, 377-89.

Holford, I. C. R., and Mattingly, G. E. G. (1979). Effects of phosphate buffering on the extraction of labile phosphate by plants and by soil tests. Aust. J. Soil Res. 17, 511-14.

Holford, I. C. R., Wedderburn, R. W. M., and Mattingly, G. E. G. (1974). A Langmuir two-surface equation as a model for phosphate adsorption by soils. J. Soil Sci. 25, 242-55.

Kurtz, T., De Turk, E. E., and Bray, R. H. (1946). Phosphate adsorption by Illinois soils. Soil Sci. 61, 111-24.

MacLean, A. J., Bishop, R. F., and Lutwick, L. E. (1953). Fertility studies on soil type. III. Phosphorus supply and requirement as shown by greenhouse studies and laboratory tests. Can. J. Agric. Sci. 33, 330-43.

Murphy, J., and Riley, J. P. (1962). A modified single solution method for the determination of phosphate in natural waters. Anal. Chim. Acta 27, 31-6.

Novais, R., and Kamprath, E. J. (1978), Phosphorus supplying capacities of previously heavily fertilized soils. Soil Sci. Soc. Am. J. 42, 931-5.

Olsen, S. R., Cole, C. V., Watanabe, F. S., and Dean, L. A. (1954). Estimation of available phosphorus in soils by extraction with sodium bicarbonate. U.S. Dep. Agric. Circ. 939.

Smillie, G. W., and Syers, J. K. (1972). Calcium fluoride formation during extraction of calcareous soils with fluoride: II. Implications to the Bray P-1 Test. Soil Sci. Soc. Am. Proc. 36, 25-30.

Williams, E. G. (1967). The intensity and quantity aspects of soil phosphate status and laboratory extraction values. An. Edafol. Agrobiol. 26, 525-46. 